\title{
Policy context as a factor of bias in the valuation of environmental goods - a dual-process theories perspective.
}

\author{
Ekaterina Nikitina* \\ Norwegian College of Fishery Science, UiT - The Arctic University of Norway, Troms $\phi$, Norway. \\ Postboks 6050 Langnes, 9037 Troms $\varnothing$ \\ ekaterina.nikitina@uit.no
}

When ecosystem services value estimates are applied in the economic assessment of environmental policies, high accuracy of these estimates is required. One of the directions in the scientific discussion on biases in stated preference (SP) valuation surveys builds on dual-process theories of judgment. The paper contributes to this literature by presenting an experiment where two types of judgment were induced via separate versus joint valuation of environmental goods. The results demonstrated that policy relevance of environmental issues, e.g., the need for conservation measures, increases emotional response, causing a larger bias in the separate design as it involves "valuation by feeling". This finding suggests that the context of a specific policy, which is often the reason for conducting SP surveys, influences the answers, thereby making the results less reliable for use in cost-benefit analysis.

Keywords: attitudes; affective valuation; behavioral economics; environmental management; marine biodiversity 


\section{Introduction}

The need for incorporating nature values into cost-benefit analysis (CBA) of environmental policies has been recognized in the modern public and academic discourse of ecosystem services conception (Fisher et al. 2008; Gómez-Baggethun et al. 2010; Liu et al. 2010; TEEB 2010; Obst, Hein, and Edens 2016). Valuation of benefits and costs of changes in provision of ecosystem services is considered in this context as a necessary step in providing such input in the economic analysis of environmental projects, including conservation strategies and mitigation of negative externalities. Unlike other potential applications, such as raising awareness, valuation of ecosystem services for the purpose of economic analysis of specific policies requires highly precise estimates (Costanza et al. 2014). Indeed, biased estimates may lead to an incorrect assessment of the welfare change related to the considered policy and may result in non-optimal decisions. ${ }^{1}$

The issue of accuracy is particularly relevant for the stated preference (SP) valuation methodology, where pursuing best practices is encouraged to minimize biases (Johnston et al. 2017). This group of techniques includes widely used contingent valuation (CV) and choice experiment (CE) survey designs for estimation of public willingness to pay (WTP) for environmental services (Hanley and Barbier 2009). Since monetary values are inferred from responses to hypothetical questions rather than from observations of actual market transactions, behavioral factors may affect the accuracy of results. For example, the influence of respondents' emotions may bias the answers (Fischer and Glenk 2011; Menzel 2013; Hanley et al. 2016).

The role of affect (emotional attitudes) has been one of the key research themes in the literature on biases in SP surveys, where dual-process theories of judgment and decision-making are often applied. Dual-process theories in behavioral literature describe thinking and decisionmaking activity of two types, named System 1 and System 2 by Kahneman (2012). However, a variety of other labels exist (Alós-Ferrer and Strack 2014). For example, in the literature related to SP valuation, definitions "valuation by feeling" and "valuation by calculation" introduced by Hsee and Rottenstreich (2004) are widely used. The latter pair of definitions captures the general idea of System 1 providing fast, affective, heuristic answers and System 2 producing the result via deliberate, rational and effortful thinking. In their review of dual-process theories, Evans and Stanovich (2013) note that the description and the interpretation of the two types of thinking and judgment differ considerably among models, and generalizations should be avoided. In this paper,

I use the terms "valuation by feeling" and "by calculation" as they are normally used in the 
literature discussing SP valuation methods. Here, I assume that the influence of affect is the distinguishing factor between the two systems and the main source of bias in "valuation by feeling". In this context, affect or emotions, associated with "valuation by feeling", differ from more stable believes and attitudes, assessed in the "calculation" mode. According to Kahneman (2012), System 1 "generates impressions, feelings, and inclinations; when endorsed by System 2 these becomes beliefs, attitudes, and intentions". These stable attitudes are what valuation studies are usually intended to elicit, avoiding biases induced by instant emotions, as affective valuations tend to be more extreme and polarized, more myopic and less sensitive to scope compared to cognitive assessments (Pham and Avnet 2009).

Indicating the presence of biases in "valuation by feeling", valuation literature often explores the individual variability of WTP on the respondents level (e.g., Hanley et al. 2016; León et al. 2014; Garrod et al. 2012) but pays little attention to the variation among the different types of valuated goods. Based on the assumption that affect is the main distinguishing factor between the two types of valuation, it is reasonable to suggest that the size of bias depends on the relative intensity of emotional response to the goods in question. A few studies investigate the heterogeneity of environmental issues as an explanatory factor of affective valuation. For example, Hanley (1996) found that the percentage of protest bids is generally higher for wildlife than for landscape. Rottenstreich and Hsee (2001) and Hsee and Rottenstreich (2004) studied the interaction between the sensitivity to scope and affect-richness of different goods. They found that respondents are more sensitive to scope in their valuation of affect-poor goods. However, little is known about the magnitude of the variation in the size of affect-induced biases and the factors explaining the difference in affect-richness. Yet these factors might be important for valuation practitioners to take into account. In particular, whether the environmental issue in question is part of the current environmental policy agenda might be an important aspect influencing the estimates. Affectinduced biases can be particularly large in the valuation of policy-relevant environmental goods ${ }^{2}$, since environmental policy issues tend to be sensitive and attract public interest, which probably makes them more affect-rich.

The question addressed in this paper is whether affect has an impact on the value estimates of policy-relevant environmental goods at a larger degree than for other, less affect-rich goods, when judgments are made relying on feelings rather than on a rational assessment of attitudes. In other words, whether the affective values depart more from the "true preferences" when an 
environmental issue is presented in an SP survey in the context of a policy change. The contribution of the present study is in defining variability in the size of biases depending on the type of goods, linking it to the policy-relevance of environmental issues (such as conservation) and raising concern about this aspect of accuracy of SP value estimates.

To address the research question, the two types of judgment should be compared. There are no clear-cut characteristics that determine whether "valuation by feeling" or "by calculation" is applied in a particular task. For example, Chang and Pham (2013) consider the relation of the task to present as one of the factors influencing rationality. Hong and Chang (2015) conclude that the type of judgment depends on whether respondents are asked to provide their own valuation or on behalf of someone else. One of the factors about survey design, which is most often examined in the literature, is joint versus separate assessment of goods or attributes, where joint representation is shown to promote rational assessment (Posavac et al. 2006; Alevy, List, and Adamowicz 2010; Sanbonmatsu et al. 2011) and reduce the influence of emotions (Ritov and Baron 2011). According to Kahneman, Ritov, and Schkade (1999), rationality is increased in the choice settings compared with the selective assessment. In a more recent work, Kahneman (2012, 361) suggests that "comparative judgement, which necessarily involves System 2, is more likely to be stable than single evaluations, which often reflects the intensity of emotional responses of System 1". This factor is particularly important in the application of the SP method, as valuation surveys are usually focused on one environmental good or project at a time.

In this paper, I present an experiment that contrasted two valuation survey designs: one presenting environmental goods in isolation, that would engage "valuation by feeling", and another based on comparative assessment of goods motivating "valuation by calculation". The results support the hypothesis that affective valuation might cause larger bias for policy-relevant environmental goods than for other ones due to increased awareness about the good. Valuation surveys that induce affect-based responses are therefore less reliable for use in policy appraisal. This can lead to a situation where larger bias appears in the value estimates of those environmental entities, for which accurate estimates are most needed.

The paper proceeds as follows. The next section states the hypothesis and describes the experiment design and procedure. Section 3 presents statistical and qualitative analysis and results. Section 4 discusses the findings and possibilities of overcoming the bias. 


\section{Hypothesis and method}

To address the question of the influence of policy-relevance of environmental goods on the degree of affective response, it is necessary to define how exactly policy-relevance influences affectrichness and what other factors may have an impact.

There is no exact and universal metrics for affect-richness, as there is no exact definition of emotion (Cabanac 2002). I suggest two general determining factors of affective response intensity of environmental goods.

The first factor is whether the environmental entity provides primarily cultural ecosystem services (according to MEA [2003] classification), such as recreation, aesthetic or symbolic value - those services that are associated with emotions. In the literature on consumer behavior, these services are defined as hedonic consumption (Hirschman and Holbrook 1982) in contrast to utilitarian consumption (Kim and Kim 2016). The assumption here is that charismatic species and those associated with recreation and emotional experience are more affect-rich and therefore will be valuated with a larger disparity between the two modes of valuation. Aesthetics and other properties attributed to cultural values have been shown to influence preferences of different types of wildlife and landscapes, where affect is assumed to play an important role (Kaplan 1987; Woods 2000). For example, Kellert (1996) identifies emotional bounding, interest for nonhuman ethical relationships, and symbolic use of species among factors shaping attitudes to different animals. Presence of cultural services is indirectly associated with policy-relevance, since these services are often in the core of environmental conflicts and trade-offs that underlie the need for policy change. Notably, the presence of these values favors the use of SP valuation methods, since relevant markets for many cultural services do not exist.

Another factor influencing affect-richness is knowledge about environmental goods. The role of awareness in judgment and decision-making has been studied in psychology and consumer behavior research fields. A well-known example is the mere-exposure effect (Zajonc 1968), which suggests that frequent encounters with an object increase a positive attitude to it. Kahneman (2012) describes the availability heuristic - the tendency to assess objects as more important by the relative ease they come to mind. Hasselström and Håkansson (2014) demonstrated that higher familiarity with a good translates into higher WTP. In this respect, the awareness of the environmental entity, increased by media coverage, can increase its affect-richness. Here, public discussions of environmental policies may contribute to a higher awareness of the environmental goods being 
valued. Thus, policy-relevance might influence the affect-richness of the good through higher awareness of it, which will result in a larger difference of values between "valuation by feeling" and "valuation by calculation".

The experiment presented in this paper is intended to test whether the degree of cultural services prevalence and the awareness factor influence the affect-richness of a good, and therefore the size of bias between "valuation by feeling" and "valuation by calculation". Another objective is to investigate possible interactions between these two factors.

In the survey experiment, I used joint and separate presentations of environmental goods to compare the two types of decision-making. The design is largely built on earlier studies (Posavac et al. 2006; Posavac et al. 2009), where a set of four national parks were introduced for joint and separate valuation. In the present experiment, a set of four marine species was presented to the respondents. Participants were asked to value either one of the four species or all of them jointly, which yielded four focal groups (groups 1-4) and one control group (group 0). It is expected that the values assigned to a species in the control group and in the relevant focal group will differ, where affect-richness of the goods would define the variation in the size of biases. Size of bias is the variable of interest in this experiment. While the variability of values assigned to each species in the control group can reflect stable preference order, the variability of bias is explained by the different levels of affect-richness, as defined by the two factors described above, where policyrelevance contributes to the intensity of affective valuation via increased awareness.

\subsection{Valuation set}

The following species were included in the survey: European lobster (Homarus gammarus), lomvi (Uria aalge), Atlantic salmon (Salmo salar), and bowhead whale (Balaena mysticetus). All four species are relevant for conservation policies in Norway, where the experiment occurred. Lomvi and bowhead whale are categorized as critically endangered and are on the Norwegian Red List. European lobster used to be defined as nearly threatened but was not included in the latest Red List. The lobster population in the Norwegian waters has been low due to overfishing. Atlantic salmon has never been categorized under Red List criteria, as the List considers the stock as a whole. Some of the river populations, however, are in poor condition, and the total number of wild salmon in Norway has been reduced by about a half since the 1980s (Anon. 2016). 
The four species vary in the degree of cultural services they provide. Here, European lobster represents mostly a marketable good. Recreational lobster fishers in Norway are not allowed to sell their catch, but it is a valuable species for personal consumption. Even if recreational fishery can be considered as providing an emotional experience, the catch is perhaps more important here than the process of fishing itself. In fact, there is no such practice as "catch-and-release" in lobster fishing, as there is for another species in the set, Atlantic salmon. Other cultural services, such as aesthetic value, are probably not very common for crustaceans either. Thus, we can see lobster as associated primarily with provisioning ecosystem services rather than cultural ones.

In contrast to lobster, lomvi is a species that is exclusively associated with cultural services in Norway. The aesthetic value of sea birds is generally high (Whelan, Şekercioğlu, and Wenny 2015), and bird watching is one of the important tourist attractions in Norway.

Atlantic salmon provides both provisioning and cultural ecosystem services (Meeren 2013). It is an iconic species in Norway. With more than 400 salmon rivers (Anon. 2016) and approximately 100 thousand fishers participating in recreational fishing annually, wild salmon is an important part of the culture for communities throughout the country (Flåten and Skonhoft 2014).

In regard to marine mammals, and whales in particular, their exceptional role as providers of aesthetic, existence and bequest values is evident in Norway and beyond. In Norway, where commercial whaling is present, whales also represents provisioning ecosystem services. However, cultural services prevail for the endangered species which are not exploited.

Considering the awareness factor, I use media coverage as a convenient indicator for comparison of the four species. Figure 1 presents the search results for the key words related to these species on the major Norwegian news web-site NRK.no. Lobster is frequently mentioned in the news, but mostly in cooking recipes, which reflects the prevalence of the provisioning services. In the context of fishing, though, the coverage is quite moderate.

Awareness of lomvi and its conservation seems to be low. As seen from Figure 1, the key word "lomvi" appears rarely in the news.

The highest media coverage among the four species is for Atlantic salmon, which can be explained by the role of recreational fishing. However, a large part of the discussion in media as well as in other public fields is about the impact of salmon aquaculture on the survival and quality of the wild salmon population. Negative externalities from salmon aquaculture, such as farmed fish 
escape and spread of parasites, are recognized as threats for wild salmon and other salmonid species (Taranger et al. 2014). Considering the large scale of salmon farming in Norway and the recent plans for its further growth (St.meld. nr. 16 2014-2015), considerable public attention to the issue is apparent. The discussions have intensified in recent years in connection to several government initiatives for regulations that would ensure sustainable growth in aquaculture production, meaning that they include measures for the mitigation of negative environmental impacts. Public debate on these regulations has increased awareness of Atlantic salmon and its conservation.

Interestingly, the bowhead whale is the least representative among the four species in the set. However, whales in general are mentioned quite often. This supports the findings of Ris (1993), who pointed to the creation of a public perception of whales shaped by environmental movements. Campaigns for the protection of whales portray a non-existent species that includes all the appealing features of different types of whales (Woods 2000). In this respect, the awareness of whales in Norway probably reflects broader trends.

Considering the two factors of affect-richness defined here, we expect a relatively high affective bias in the valuation of the bowhead whale and Atlantic salmon. These species are characterized by high awareness about them in Norway and a high presence of cultural ecosystem services. A relatively low affect-richness, and therefore a smaller bias, is assumed to be found in the valuation of lobster, as it mostly represents provisioning ecosystem services and its awareness factor is smaller than for other species in the set. For lomvi, the prevalence of cultural services might result in a high affective response, but the low awareness of the species may limit the bias.

[Figure 1 near here]

\subsection{Experiment procedure}

The survey experiment was conducted online in February 2017. In total, 223 Norwegian residents participated. The respondents were recruited by Norstat Norge AS, and representativeness was ensured among age, gender and location. ${ }^{3}$ The participants were automatically and randomly assigned one of the 5 groups as they entered the survey page. Thus, the number of respondents in each group was unequal but comparable (49 in group 0; 47 in group 1; 39 in group 2; 45 in group 3 ; and 43 in group 4). 
The structure of the survey was the same in all groups (Appendix 1). First, general instructions and brief information about all species accompanied by color pictures were given, and the need for conservation of these animals was explained. Participants in the focal groups were informed about the random process of assigning species for valuation, which was explained by the need to limit the time to complete the survey (a procedure similar to one used by Posavac et al. [2006]). No such instructions were given to the participants in the control group.

In the control group, respondents were asked to distribute a fixed budget between the four species-specific conservation projects. The main valuation question was formulated as a constantsum allocation task:

"Consider a hypothetical situation. A state-owned environmental fund has NOK 40 million available for four projects. Each project is designed for conservation of one of the species, where the measures are taken to reduce existing threats to their survival. How do you think the budget should be distributed? Write a sum (in millions NOK) in the boxes for each project, so that the total sum becomes 40 million. It is possible to assign the whole budget or zero to a project."

In the focal groups, the last part of the question was formulated differently:

"How much of these 40 million should be assigned to the lobster/lomvi/wild salmon/bowhead whale-project in your opinion?"

Here, the respondents answered by moving the slider on a scale from 0 to 40 .

To verify the assumptions made on the relative affect-richness of the species in the set, additional questions were included before and after the valuation part. The first part (questions 18) comprised a quiz about the species, which is also a common element in many real SP surveys. The proportion of right answers would give some indication about the degree of awareness. In the focal groups, the quiz included only questions about focal species. The questions were roughly grouped under five topics: biology of the animal, human impact, conservation, myths and mediainfluenced information, and animal welfare. This categorization is done to explore the possible influence of awareness content; what participants know about the animals might be as important as how much they know. In the control group, the quiz comprised only general questions on the biology of the four species in order to prevent emotional response, as the quiz was also assumed to contribute to the engaging "valuation by feeling" in the focal groups and "valuation by calculation" in the control group. 
Following the valuation question, participants were offered a list of 6 factors (with the possibility of adding their own), for which they indicated the degree of influence on their decision on a scale from 1 to 3 ( 1 - did not consider, 2 - considered to some extent, 3 - considered to a large extent). These factors were importance of the species for the ecosystem, importance of the species for the Norwegian economy, importance of the species for society and future generations, importance of the species for the respondent personally, budget restrictions and participants' assumptions about the project's costs, and fairness. The importance of cultural services is tested here.

In addition to the valuation question that required a distribution of the budget, another preference-elicitation question was used which asked respondents to choose one of the four conservation programs that would receive a donation on behalf of the participant. It was followed by a non-compulsory open question about the motives of the answer. These answers provide additional information on the affect-richness of the environmental goods in the set.

\section{Data analysis and results}

\subsection{Statistical analysis and results}

Unlike earlier valuation experiments using a fixed-budget allocation task for a homogenous set of environmental goods (Posavac et al. 2006), the present study does not assume equal proportions in the joint representation of goods. This means that the average proportion of the budget allocated to each of the four different species in the joint design might not be equal to 0.25 (NOK 10 million).

As seen in the Table 1, the mean values in group 0 are close to NOK 10 million, but projects 1 and 3 are valued higher than projects 2 and 4. Analysis of variance has indicated a significant difference between the means at the $95 \%$ confidence level: $F(3,192)=3.51, p=0.02 .{ }^{4}$ A post hoc Tukey test shows significant difference between all pairs of groups, except for groups 1 and 3 and groups 2 and 4 . Thus, the mean values of the focal groups should be compared with the actual mean values of the control group rather than with the NOK 10 million baseline.

[Table 1 near here]

Figure 2 illustrates the distribution of the budget allocations (in million NOK) that compares values in the control and the relevant focal group for each species. For each project, the distribution of 
values in the control and focal groups was examined graphically for non-normality and tested for heteroscedasticity. It is clear from Figure 2 that in most groups the distribution of values is skewed. A Levene's test rejected the hypothesis of the equal variances of the control and focal groups for all projects except for the first one (p-values are $0.93 ; 0.022 ; 0.00$; and 0.031 ). Taking into account the relative robustness of the parametric hypothesis testing methods to the violations of normality assumption (Algina, Oshima, and Lin 1994), the difference between means in each pair of values was tested using a Welch's $T$ test. Test results did not suggest a statistically significant difference between joint and selective representation in the valuation of European lobster $(\mathrm{t}=-0.55381, \mathrm{p}$ value $=0.581)$, but it indicated a difference for the three remaining projects $(\mathrm{t}=-2.12$ and $\mathrm{p}$ value $=0.037 ; \mathrm{t}=-3.26$ and $\mathrm{p}$-value $=0.002 ; \mathrm{t}=-3.84$, and $\mathrm{p}$-value $=0.000$ ).

[Figure 2 near here]

As seen in Figure 2, the average budget allocated to a project in the focal groups are higher than in the respective control group. However, for some species, the difference is larger than for others. The largest disparity is observed in the valuation of the bowhead whale, while for the European lobster, the change is barely noticeable. Here, I am interested in comparing the magnitudes of the effect among the four projects. I compute effect sizes as a quantitative measure of the effects, which has been a common procedure in behavioral research (McGrath and Meyer 2006; Fritz et al. 2012). Among the variety of effect sizes measures, Cohen's $d$ is most often used in experimental studies where the main interest is in quantifying the difference in the effect of a manipulation on group means (McGrath and Meyer 2006).

Cohen's $d$ measures the difference between the means of a continuous variable for the two groups defined by a binary variable. In this study, I compute the sample standardized mean difference as follows:

$$
d=\frac{\bar{Y}_{1}-\bar{Y}_{2}}{S_{\text {pooled }}}
$$

where $\bar{Y}_{1}$ and $\bar{Y}_{2}$ are the means of the focal and control groups, and $S_{\text {pooled }}$ is the pooled sample standard deviation calculated with the total sample size $N$ in the denominator: 


$$
S_{\text {pooled }}=\sqrt{\frac{\sum(Y-\bar{Y})^{2}}{N}}
$$

Effect sizes, summarized in Table 2, give a quantitative indicator for the comparison between the effects associated with the affective valuation of different projects.

\section{[Table 2 near here]}

General benchmarks for the effect size proposed by Cohen (1988) interpret the value of $d$ as equal to $0.8,0.5$ and 0.2 as representing a large, small and medium effect size, respectively. However, in each study the benchmarks should be defined depending on the nature of the investigated effects (Fritz et al. 2012). In the present study, the effect sizes are calculated for the purpose of comparison between the four projects. Therefore, the relative effect size is more important here than the absolute value of $d$. In applying general benchmarks, however, a large effect can be suggested for project 4, medium effects for projects 2 and 3, and a small effect for the first project.

\subsection{Qualitative analysis and results}

The variability in the size of bias seems to correspond to the assumed relative affect-richness of the four environmental goods. However, as there is no formal theory or metrics for the assessment, the assumptions underpinning the hypothesis is quite uncertain. Whether the awareness of the good and the level of cultural services it represents is high or low is largely a subjective judgment. It is therefore useful to examine respondents' answers for additional evidence.

The qualitative data comprise the quiz answers, answers about factors influencing valuation and comments to the open question about the motives for the choice of the project that would receive a one-time donation. The quiz results were first analyzed based on the average number of correct answers (Figure 3a). Then, the answers to each question were considered. The six factors of valuation were assessed by their average score for each species (Figure 3b). The total number of respondents who have chosen the species in the donation question (Figure 3c) provides additional information on the relative affect-richness. The comments to this question are examined in relation to awareness and cultural services factors' influence. The information from all three sources 
combined provides grounds for verifying whether the assumptions on the relative affect-richness of the four species were correct.

[Figure 3a), b), c) near here]

\subsubsection{European lobster}

It was earlier suggested that the awareness of this species in Norway is rather low and that cultural ecosystem services are not represented as much as they are in other species. A relatively low affectrichness is then assumed. Taking this assumption into account, the highest correctness score in the quiz (Figure 3a) is an unexpected result. However, the two factors may influence affective response intensity in combination. Thus, the content of the knowledge (whether this knowledge is about cultural or provisioning ecosystem services) might be important. Respondents in group 1 demonstrated quite a good knowledge of issues relevant to the exploitation of the species. Most participants answered correctly to the questions about overfishing problems and fishing rules. However, people seem to have little interest in the life of the lobster itself. For example, there were over $50 \%$ incorrect answers about its diet. Answers to another question showed that 39 out of 47 respondents believed that there is nothing wrong with boiling lobster alive. This supports the idea that people generally think about lobster in terms of provisioning services. High awareness of the provisioning services might not contribute much to the level of affect-richness.

Interestingly, however, among the 6 factors influencing the valuation, the importance of preserving the lobster for society and future generations has the highest average score (Figure $2 \mathrm{~b}$ ). This factor reflects the existence value. A possible explanation for this result is that provisioning and cultural values are connected in the exploited marine species. The willingness to preserve the species might reflect a willingness to continue its exploitation in the future. This proposition is supported by the fact that the importance of lobster for the individual respondent received the lowest score among the factors defining valuation (Figure 2b). Cultural services, however, are not totally absent for this species, as evidenced by the comments to the donation question, as its importance for coastal culture has been mentioned often.

There is evidence of the importance of the awareness and cultural services factor combination, as some respondents pointed to the need for research and informing the public about the need to preserve the species: 
"All people on the coast need to know more about how threatened the lobster stock is and that it is possible to improve the situation."

Generally, the qualitative data support the assumption about low affect-richness of the first species in the set.

\subsubsection{Lomvi}

The analysis of the quiz answers suggests a relatively low awareness level for this species. This concerns all types of questions in the quiz, including those about anthropogenic impact. For example, 18 out of 39 respondents do not believe that overfishing is one of the causes of lomvi population decline.

The purely hedonic nature of this environmental good in the Norwegian context is reflected in the reported relative importance of the six valuation factors in group 2, where the economic importance received the lowest score (Figure 3b).

An emphasis on aesthetic value is noticeable in the responses to the donation question. Participants used a more emotional style to describe their attitude to the species than did the previous group:

"I love birds."

"I like birds, I think they are beautiful and I would like to protect all of them."

"I am afraid that lomvi is threatened."

Interestingly, some respondents compare the beauty of the bird with other species in the set:

"I do not like lobster."

"The bird is cuter than fish or lobster."

Several respondents pointed to the importance of the place the species belongs to:

"It is a Norwegian bird."

"I have chosen lomvi because it belongs to our coastal areas."

Once again, in this group the respondents themselves pointed to the role of awareness as a factor of affect-richness:

"This survey has made me more aware about lomvi." 
The qualitative analysis provides some evidence for the assumption that the prevalence of cultural services makes this species potentially highly affect-rich, but due to low awareness, the affective response remains low. Some of the respondents, however, pointed to the media coverage related to lomvi:

"It is most visible."

"According to what is communicated via TV programs, situation is critical for lomvi."

It is not clear, however, whether the respondents referred to the "visibility" of seabirds in general.

\subsubsection{Atlantic salmon}

Respondents in group 3 gave the least number of correct answers to the quiz questions (Figure $3 a$ ). As in the previous groups discussed above, a more detailed review of the answers is made to assess the influence of the content, which suggested high awareness of the aquaculture problem. For example, 39 out of 45 respondents believe that cultured salmon has genes that are not found in wild salmon. The majority (26 participants) also believe that 2-3 lice is a fatal level of infection for smolt. Both statements are wrong, but the answers demonstrate how the image of aquaculture effects on wild salmon is created through media and public discussion.

Importance for society and future generations obtained the highest score among the 6 valuation factors (Figure 3b). However, as in the case of lobster, this may reflect the importance of both provisioning and cultural values. The inseparable nature of these values associated with wild salmon in Norway is also seen in the respondents' comments, where provisioning services (salmon as a food resource) and economic importance were the most commonly named reasons selected.

The largest number of survey participants were willing to make a donation to the salmon conservation program (Figure 3c), which points to its high affect-richness. Many of these choices are not commented, however. As one of the respondents explained,

"It is difficult to choose - it just tended toward salmon."

A number of participants explained their choice by the need to protect wild salmon against the effects of aquaculture:

"Salmon is in danger because of aquaculture."

"It is threatened by aquaculture." 
"It is a much-threatened species that is under pressure of the commercial production of a less valuable species."

"If this species can be preserved and co-exist with aquaculture, it would be a miracle."

These comments support the hypothesis that policy relevance increases awareness and therefore the affect-richness of this environmental good. In the case of wild salmon, the awareness through policy discussions is related to existence value, as the stock is affected negatively by aquaculture.

\subsubsection{Bowhead whale}

The quiz answers in group 4 indicate that awareness of this species might be influenced by the image of the "super-whale" (Ris 1993), whose survival is threatened by humans. In other words, the content of the knowledge about the whale relates to its existence value. The fact that humans are causing the damage seems to be important in this context: 30 out of 43 respondents did not believe that the whale has any natural predators, which may emphasize that the only real predator for these animals is humans. A high level of agreement and correctness in the answers to questions about whaling also reveals that people are aware of the human impact. Interestingly, 22 respondents in group 4 chose the right answer to question 4, stating that the Spitsbergen population of this whale is less than 100. However, only 8 respondents chose the next variant, which stated that the population is approximately 500 individuals. The first variant is more extreme, which probably corresponds with the general perception of the whale species as being extremely endangered.

Management context does not increase the affect-richness for this species, as it does not seem to be communicated to or perceived by the public. In the question about the International Whaling Commission (IWC), the largest segment, 18 respondents, did not believe that there was a total ban on commercial whaling, probably because they have witnessed the commercial exploitation of whales in Norway. The fact that the country objected to the moratorium did not appear to be well-known. Instead, a commonly shared stereotype appeared in the answers to question 7, where most of the respondents agreed with the statement that bowhead whales provide products used in cosmetics and perfumes, even though this statement used to apply to another species.

As in group 2, the lowest score was given to the economic importance of the species (Figure $3 b$ ), pointing to the prevalence of cultural services. However, regulative services were also 
considered by respondents, as the importance for the ecosystem received the highest score. This factor also prevailed in the comments to the donation question:

"Whales are large, important animals at the top of food chain and are vital for well-functioning ecosystems. I also think this is a more global problem than for other animals here, and the whales have fewer "helpers" along the coast of Norway."

Another group of answers points to the role of both awareness and cultural services. Aesthetic value apparently shapes attitudes and is influenced by the general image of whales as intelligent, beautiful and charismatic animals. As expected, people often refer to whales in general, rather than to a particular species:

"Fantastic animal."

"Whales are nice."

"Whales are more intelligent, this is an important factor for choosing them among the other projects."

"As far as I know, bowhead whales and some other whale species are under threat of extinction."

Concern about human impact is visible here as well:

"We need to recover the whale stock since it was slaughtered by our ancestors."

The results provide some evidence for the assumption that prevalence of cultural services and the way they are communicated to the public in the case of whales results in its high affect-richness.

\section{Discussion}

The valuation experiment presented in this paper was designed to test the hypothesis of the dependence of affective response intensity in the valuation of different environmental goods on two factors: prevalence of cultural ecosystem services and awareness. The results illustrated in Figure 2 show that the difference in the size of affect-induced bias corresponds to the assumed relative affect-richness of the fours species assessed based on these two factors. Here, the disparity between "valuation by feeling" and "valuation by calculation" is small for two of the species in the set, European lobster and lomvi, and large for Atlantic salmon and bowhead whale.

The purpose of the qualitative analysis of the participants' responses was to ascertain that the suggested relative affect-richness of the environmental goods is valid. Such analysis is always 
characterized by some degree of subjectivity. Thus, interpretation of the data presented in the paper might be disputed. However, many of the answers, especially the respondents' comments on the donation question, are unambiguous and provide solid ground for interpretation. The answers given by participants suggest that affect-richness is low for European lobster due to the prevalence of provisioning ecosystem services, even if awareness of this species in Norway is generally high. A slightly higher affect-induced bias in the valuation of lomvi is probably explained by its high aesthetic value, but affect-richness is still relatively low due to a lack of knowledge about this bird. Wild salmon and bowhead whale appeared to be highly affect-rich due to strong awareness and high representation of cultural ecosystem services.

Qualitative analysis also reveals how the two factors influence affect-richness in interaction. It was found that the content of knowledge of the environmental good is likely to determine affect intensity, while the amount and correctness of that knowledge is less important. As the answers of group 1 suggest, when the public is well-informed about provisioning services, such as the exploitation of lobster, there is no major increase in the intensity of affective response. However, if awareness concerns existence value, coastal culture, aesthetics or other cultural services, as in the case of wild salmon and bowhead whale valuation, the result is a high affectinduced bias. Awareness of anthropogenic impact, such as pollution and overexploitation, seems to be an additional attribute influencing the degree of affective response to an environmental good.

For example, in the valuation of Atlantic salmon, awareness of the negative impact of aquaculture was an important factor in making this environmental good highly affect-rich. Aquaculture externalities, including the negative effects on wild salmon, is a widely discussed issue in Norway, as the authorities have been developing regulations for the aquaculture industry in recent years. Atlantic salmon is often the subject of media coverage, as seen from Figure 1, and much of the information about it reaching public relates to this policy issue. The influence of policy-relevance in increasing affect-richness is particularly visible for this species, compared with others in the set.

The results of the statistical analysis (Figure 2), verified qualitatively, support the hypothesis that awareness of environmental goods is a factor influencing affective response intensity. Moreover, the awareness factor and cultural services factor influence affect-richness in combination. Since the presence of cultural ecosystem services is often the reason SP methods are preferred to revealed preference, this combination is likely to occur in surveys made for the purpose 
of informing decision-makers of the value of policy-relevant goods. This leads to a situation where a larger bias appears in the valuation of environmental goods for which accurate results are most needed.

The way this problem can be addressed depends on the theoretical standpoint. Assuming that valuation through preference elicitation is possible in principle, one approach can be to ensure that the survey design encourages the use of System 2, or "valuation by calculation". For example, joint valuation will be preferable, as it reveals more stable attitudes. In this regard, CE techniques have been suggested as a joint valuation design (Alevy, List, and Adamowicz 2010). In CE, multiple attributes are presented together in a trade-off setting, requiring rational consideration of alternatives in making choices. Using this technique, however, is not always possible, as many environmental goods are not normally perceived in terms of attributes (Johnston et al. 2017).

Another theoretical viewpoint, supported by a body of behavioral literature, suggests that due to the context-dependency of preferences, SP is not a valid approach to valuation. Kahneman, Ritov, and Schkade $(1999,228)$ argue that "people are better described as having attitudes rather than preferences". Moreover, attitudes are context-dependent. They suggest that biases in SP valuation result from basic cognitive processes and cannot be eliminated by improved survey design.

From this theoretical viewpoint, even "valuation by calculation" cannot provide valid results, and therefore SP cannot be recommended, especially for the purpose of informing environmental policy. Revealed preferences methods can be an appropriate option in this case, as the data-generating process is not influenced by the researcher, thus limiting the issue of accuracy to the way the data are processed. 


\section{Footnotes}

1. The discussion on the (lack of) use of valuation results in environmental policies is beyond the scope of the present paper. Laurans and Mermet (2014), Guo and Kildow (2015), and Marre et al. (2016) provide an overview of the issue.

2. The terms "environmental goods" and "environmental services" are used interchangeably in this paper.

3. The recruiting policy can be found at the company website: http://www.norstat.co.uk/methods/onlinedata-collection/

4. One-way analysis of variance was applied here despite the fact that each respondent provided four values, which makes the observations dependent. For the given data structure, however, this statistical method was more appropriate than within-subject analysis of variance. 


\section{References}

Alevy, Jonathan, John List, and Wiktor Adamowicz. 2010. "How Can Behavioral Economics Inform NonMarket Valuation? An Example from the Preference Reversal Literature." NBER Working Paper Series:16036. doi: 10.3386/w16036.

Algina, James, T. C. Oshima, and Wen-Ying Lin. 1994. "Type I Error Rates for Welch's Test and James's Second-Order Test Under Nonnormality and Inequality of Variance When There Are Two Groups." Journal of Educational Statistics 19 (3):275-291. doi:10.3102/10769986019003275.

Alós-Ferrer, C., and F. Strack. 2014. "From Dual Processes to Multiple Selves: Implications for Economic Behavior." Journal of Economic Psychology 41:1-11. doi: 10.1016/j.joep.2013.12.005.

Anon. 2016. Status for norske laksebestander i 2016. Rapport fra Vitenskapelig råd for lakseforvaltning nr. $9,190 \mathrm{~s}$.

Cabanac, Michel. 2002. "What is Emotion?" Behavioural Processes 60 (2):69-83. doi: https://doi.org/10.1016/S0376-6357(02)00078-5.

Chang, Hannah H., and Michel Tuan Pham. 2013. "Affect as a Decision-Making System of the Present." Journal of Consumer Research 40 (1):42-63. doi: 10.1086/668644.

Cohen, Jacob. 1988. Statistical power analysis for the behavioral sciences. 2nd ed. ed. Hillsdale, N. J: Laurence Erlbaum.

Costanza, Robert, Rudolf de Groot, Paul Sutton, Sander van der Ploeg, Sharolyn J. Anderson, Ida Kubiszewski, Stephen Farber, and R. Kerry Turner. 2014. "Changes in the Global Value of Ecosystem Services." Global Environmental Change 26:152-158. doi: http://dx.doi.org/10.1016/j.gloenvcha.2014.04.002.

Evans, Jonathan St B. T., and Keith E. Stanovich. 2013. "Dual-Process Theories of Higher Cognition." Perspectives on Psychological Science 8 (3):223-241. doi: 10.1177/1745691612460685.

Fischer, Anke, and Klaus Glenk. 2011. "One Model Fits All? — On the Moderating Role of Emotional Engagement and Confusion in the Elicitation of Preferences for Climate Change Adaptation Policies." Ecological Economics 70 (6):1178-1188. doi: 10.1016/j.ecolecon.2011.01.014.

Fisher, Brendan, Kerry Turner, Matthew Zylstra, Roy Brouwer, Rudolf Groot, Stephen Farber, Paul Ferraro, et al. 2008. "Ecosystem Services and Economic Theory: Integration For Policy-Relevant Research." Ecological Applications 18 (8):2050-2067. doi: 10.1890/07-1537.1.

Flåten, Ola, and Anders Skonhoft. 2014. Naturressursenes økonomi. Oslo: Gyldendal akademisk.

Fritz, Catherine O., Peter E. Morris, Jennifer J. Richler, and Isabel Gauthier. 2012. "Effect Size Estimates: Current Use, Calculations, and Interpretation." Journal of Experimental Psychology: General 141 (1):2-18. doi: 10.1037/a0024338.

Garrod, Guy, Eric Ruto, Ken Willis, and Neil Powe. 2012. "Heterogeneity of Preferences for the Benefits of Environmental Stewardship: A Latent-Class Approach." Ecological Economics 76:104-111. doi: 10.1016/j.ecolecon.2012.02.011.

Gómez-Baggethun, Erik, Rudolf de Groot, Pedro L. Lomas, and Carlos Montes. 2010. "The History of Ecosystem Services in Economic Theory and Practice: From Early Notions to Markets and Payment Schemes." Ecological Economics 69 (6):1209-1218. doi: http://dx.doi.org/10.1016/j.ecolecon.2009.11.007.

Guo, Jing, and Judith Kildow. 2015. "The Gap Between Science and Policy: Assessing the Use of Nonmarket Valuation in Estuarine Management Based on a Case Study of US Federally Managed Estuaries." Ocean and Coastal Management 108:20-26. doi: 10.1016/j.ocecoaman.2014.09.017.

Hanley, Nick. 1996. "Ethical Beliefs and Behaviour in Contingent Valuation Surveys." Journal of Environmental Planning and Management 39 (2):255-272. doi: 10.1080/09640569612598.

Hanley, Nick, and Edward B. Barbier. 2009. Pricing nature: cost-benefit analysis and environmental policy. Cheltenham: Edward Elgar.

Hanley, Nick, Christopher Boyce, Mikołaj Czajkowski, Steve Tucker, Charles Noussair, and Michael Townsend. 2016. "Sad or Happy? The Effects of Emotions on Stated Preferences for 
Environmental Goods." Environmental and Resource Economics:1-26. doi: 10.1007/s10640-0160048-9.

Hasselström, Linus, and Cecilia Håkansson. 2014. "Detailed vs. Fuzzy Information in Non-Market Valuation Studies: the Role of Familiarity." Journal of Environmental Planning and Management 57 (1):123-143. doi: 10.1080/09640568.2012.736370.

Hirschman, Elizabeth C., and Morris B. Holbrook. 1982. "Hedonic Consumption: Emerging Concepts, Methods and Propositions." Journal of Marketing 46 (3):92-101. doi: 10.2307/1251707.

Hong, J., and H. H. Chang. 2015. "“I" Follow My Heart and "We" Rely on Reasons: The Impact of SelfConstrual on Reliance on Feelings Versus Reasons in Decision Making." Journal of Consumer Research 41 (6):1392-1411. doi: 10.1086/68008.

Hsee, Christopher K., and Yuval Rottenstreich. 2004. "Music, Pandas, and Muggers: On the Affective Psychology of Value." Journal of Experimental Psychology: General 133 (1):23-30.

Johnston, Robert J., Kevin J. Boyle, Wiktor Adamowicz, Jeff Bennett, Roy Brouwer, Trudy Ann Cameron, W. Michael Hanemann, et al. 2017. "Contemporary Guidance for Stated Preference Studies." Journal of the Association of Environmental and Resource Economists 4 (2):319-405. doi: 10.1086/691697.

Kahneman, Daniel. 2012. Thinking, fast and slow. London: Penguin Books.

Kahneman, Daniel, Ilana Ritov, and David Schkade. 1999. "Economic Preferences or Attitude Expressions?: An Analysis of Dollar Responses to Public Issues." Journal of Risk and Uncertainty 19 (1):203-235. doi: 10.1023/A:1007835629236.

Kaplan, Stephen. 1987. "Aesthetics, Affect, and Cognition: Environmental Preference From an Evolutionary Perspective." Environment and Behavior 19 (1):3-32.

Kellert, Stephen R. 1996. The value of life: biological diversity and human society. Washington, D.C: Island Press.

Kim, Sungeun, and Jungkeun Kim. 2016. "The Influence of Hedonic Versus Utilitarian Consumption Situations on the Compromise Effect." Marketing Letters 27 (2):387-401. doi: 10.1007/s11002014-9331-0.

Laurans, Yann, and Laurent Mermet. 2014. "Ecosystem Services Economic Valuation, Decision-Support System or Advocacy?" Ecosystem Services 7:98-105. doi: http://dx.doi.org/10.1016/j.ecoser.2013.10.002.

León, C. J., J. E. Araña, W. M. Hanemann, and P. Riera. 2014. "Heterogeneity and Emotions in the Valuation of Non-Use Damages Caused by Oil Spills." Ecological Economics 97:129-139. doi: 10.1016/j.ecolecon.2013.10.010.

Liu, S., R. Costanza, S. Farber, and A. Troy. 2010. "Valuing Ecosystem Services. Theory, Practice, and the Need for a Transdisciplinary Synthesis." Annals of the New York Academy of Scences 1185:54-78.

Marre, Jean-Baptiste, Olivier Thébaud, Sean Pascoe, Sarah Jennings, Jean Boncoeur, and Louisa Coglan. 2016. "Is Economic Valuation of Ecosystem Services Useful to Decision-Makers? Lessons Learned from Australian Coastal and Marine Management." Journal of Environmental Management 178:52-62. doi: http://dx.doi.org/10.1016/j.jenvman.2016.04.014.

McGrath, Robert E., and Gregory J. Meyer. 2006. "When Effect Sizes Disagree: The Case of "r" and "d"." Psychological Methods 11 (4):386-401. doi: 10.1037/1082-989X.11.4.386.

Meeren, G. I. v. d. (2013). Kasusstudie: Villaks og oppdrettslaks i et фkosystemtjenesteperspektiv (Vol. nr. 5/2013). Bergen: Havforskningsinstituttet.

Menzel, S. 2013. "Are Emotions to Blame? - The Impact of Non-Analytical Information Processing on Decision-Making and Implications for Fostering Sustainability." Ecological Economics 96:71-78. doi: 10.1016/j.ecolecon.2013.10.001.

MEA (Millennium Ecosystem Assessment) 2003. Ecosystems and human well-being : a framework for assessment. Edited by Joseph Alcamo and Elena M. Bennett. Washington, D.C: Island Press. 
Obst, Carl, Lars Hein, and Bram Edens. 2016. "National Accounting and the Valuation of Ecosystem Assets and Their Services." Environmental and Resource Economics 64 (1):1-23. doi: 10.1007/s10640-015-9921-1.

Pham, Michel Tuan, and Tamar Avnet. 2009. "Contingent Reliance on the Affect Heuristic as a Function of Regulatory Focus." Organizational Behavior and Human Decision Processes 108 (2):267-278. doi: http://doi.org/10.1016/j.obhdp.2008.10.001.

Posavac, Steven S., J. Josko Brakus, Shailendra Pratap Jain, and Maria L. Cronley. 2006. "Selective Assessment and Positivity Bias in Environmental Valuation." Journal of Experimental Psychology: Applied 12 (1):43-49. doi: 10.1037/1076-898X.12.1.43.

Posavac, Steven S., J. Joško Brakus, Maria L. Cronley, and Shailendra Pratap Jain. 2009. "On Assuaging Positive Bias in Environmental Value Elicitation." Journal of Economic Psychology 30 (3):482489. doi: 10.1016/j.joep.2008.07.007.

Ris, M. 1993. "Conflicting Cultural Values: Whale Tourism in Northern Norway. " Arctic, 46(2), 156-163.

Ritov, Ilana, and Jonathan Baron. 2011. "Joint Presentation Reduces the Effect of Emotion on Evaluation of Public Actions." Cognition \& Emotion 25 (4):657-675. doi: 10.1080/02699931.2010.512512.

Rottenstreich, Yuval, and Christopher K. Hsee. 2001. "Money, Kisses, and Electric Shocks: On the Affective Psychology of Risk." Psychological Science 12 (3):185-190. doi: 10.1111/14679280.00334.

Sanbonmatsu, David M., Sam Vanous, Christine Hook, Steven S. Posavac, and Frank R. Kardes. 2011. "Whither the Alternatives: Determinants and Consequences of Selective Versus Comparative Judgemental Processing." Thinking \& Reasoning 17 (4):367-386. doi: 10.1080/13546783.2011.625659.

St.meld. nr. 16. 2014-2015. Forutsigbar og miljфmessig barekraftig vekst i norsk lakse- og фrretoppdrett. Oslo: Nærings- og fiskeridepartementet.

Taranger, Geir Lasse, Ørjan Karlsen, Raymond Bannister, Kevin Glover, Vivian Husa, Egil Karlsbakk, Bjørn Olav Kvamme, et al. 2014. "Risk Assessment of the Environmental Impact of Norwegian Atlantic Salmon Farming." ICES Journal of Marine Science. doi: 10.1093/icesjms/fsu132.

TEEB (The Economics of Ecosystems and Biodiversity) 2010. The Economics of Ecosystems and Biodiversity: Mainstreaming the Economics of Nature: A Synthesis of the Approach, Conclusions and Recommendations of TEEB.

Whelan, Christopher J., Çağan H. Şekercioğlu, and Daniel G. Wenny. 2015. "Why Birds Matter: From Economic Ornithology to Ecosystem Services." Journal of ornithology 156 (Supplement):227238. doi: https://doi.org/10.1007/s10336-015-1229-y

Woods, Barbara. 2000. "Beauty and the Beast: Preferences for Animals in Australia." Journal of Tourism Studies 11 (2):25-35.

Zajonc, Robert B. 1968. "Attitudinal Effects of Mere Exposure." Journal of Personality and Social Psychology 9 (2, Pt.2):1-27. doi: 10.1037/h0025848. 
Appendix 1. Survey text and structure (supplemental material) 


\section{Tables}

Table 1. Allocation of the NOK 40 million among the four conservation projects in the control group

\begin{tabular}{|l|l|l|}
\hline Conservation project & $\begin{array}{l}\text { Mean allocation, } \\
\text { million NOK }\end{array}$ & St. error \\
\hline 1 - European lobster & 11.43 & 1.01 \\
\hline 2 - Lomvi & 8.98 & 0.66 \\
\hline 3 - Atlantic salmon & 11.04 & 0.76 \\
\hline 4 - Bowhead whale & 8.55 & 0.59 \\
\hline
\end{tabular}


Table 2. Effect sizes for the four projects

\begin{tabular}{|l|l|}
\hline Conservation project & $\begin{array}{l}\text { Estimated effect size } \\
\text { (Cohen's d) for the } \\
\text { difference in valuation } \\
\text { between the control } \\
\text { and focal group }\end{array}$ \\
\hline 1 - European lobster & 0.11 \\
\hline 2 - Lomvi & 0.42 \\
\hline 3 - Atlantic salmon & 0.66 \\
\hline 4 - Bowhead whale & 0.77 \\
\hline
\end{tabular}




\section{Figures}

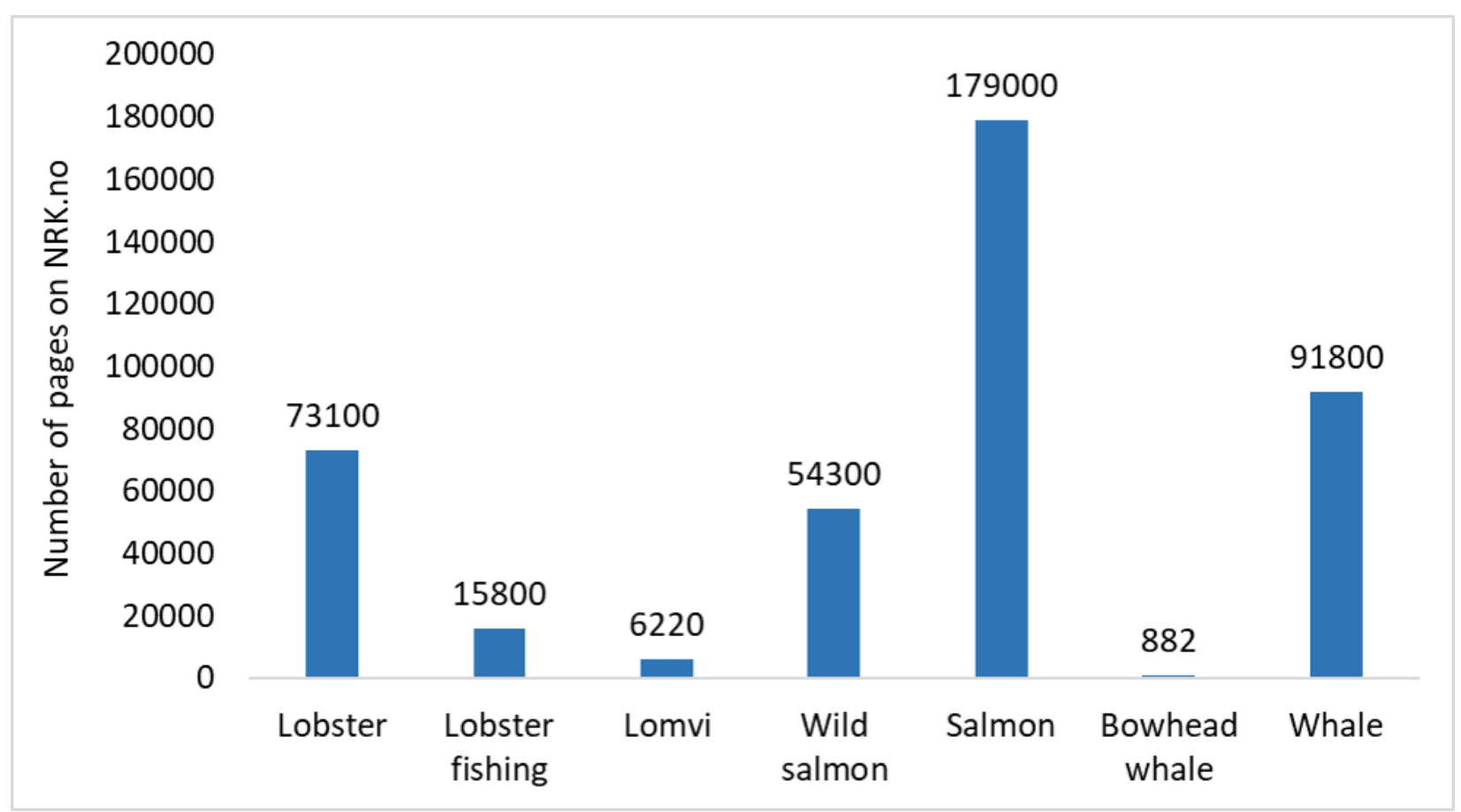

Figure 1. Approximate number of pages on NRK.no containing the names of the four species per 24 May 2017 (Google search results). 


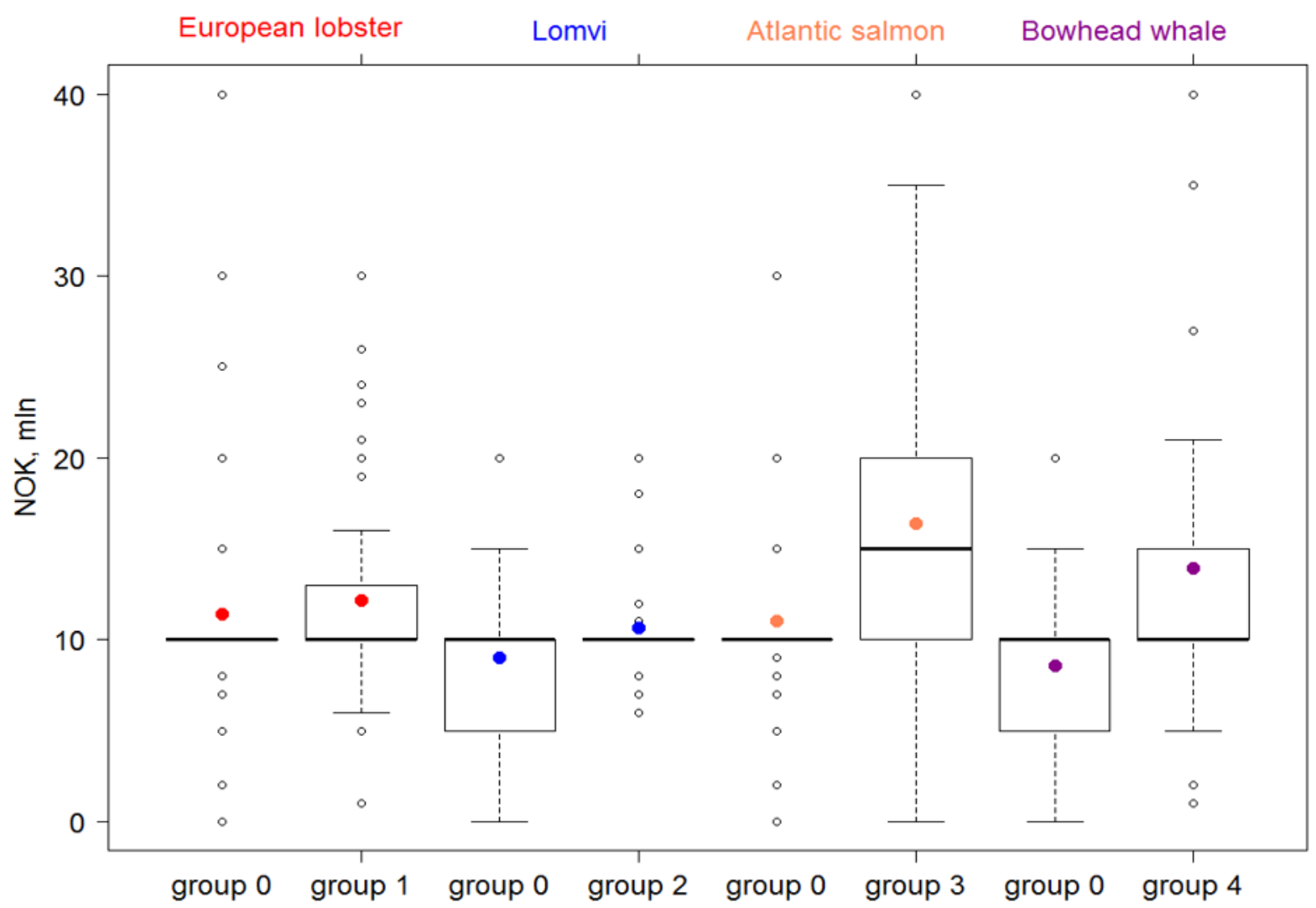

Figure 2. Difference between the mean allocation of the fixed budget (NOK 40 million) in the control (group 0) and focal groups (1-4) for the four hypothetical conservation projects. Colored dots indicate the means. 


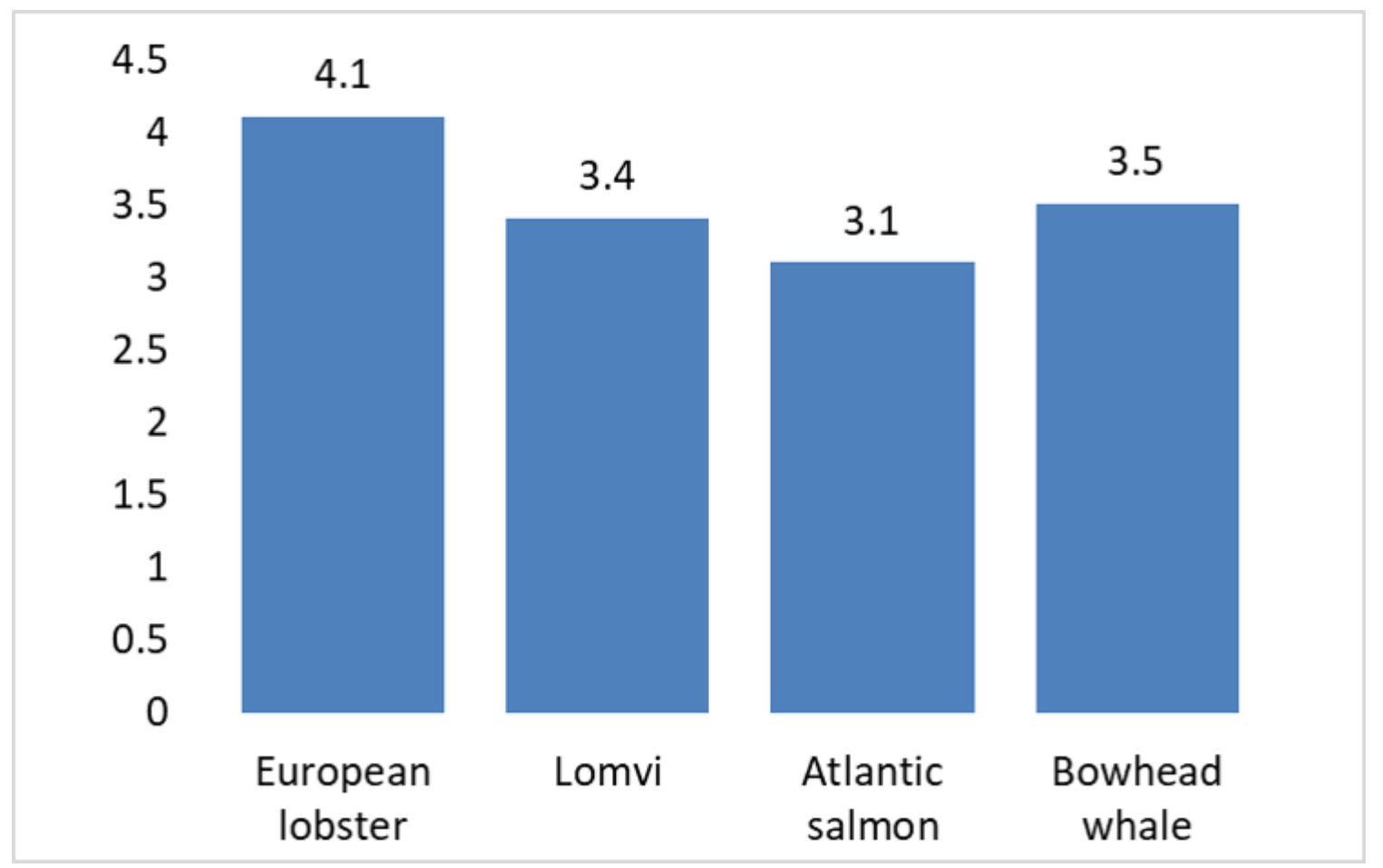

Figure 3a) The average number of correct answers in the quiz in the focal group 


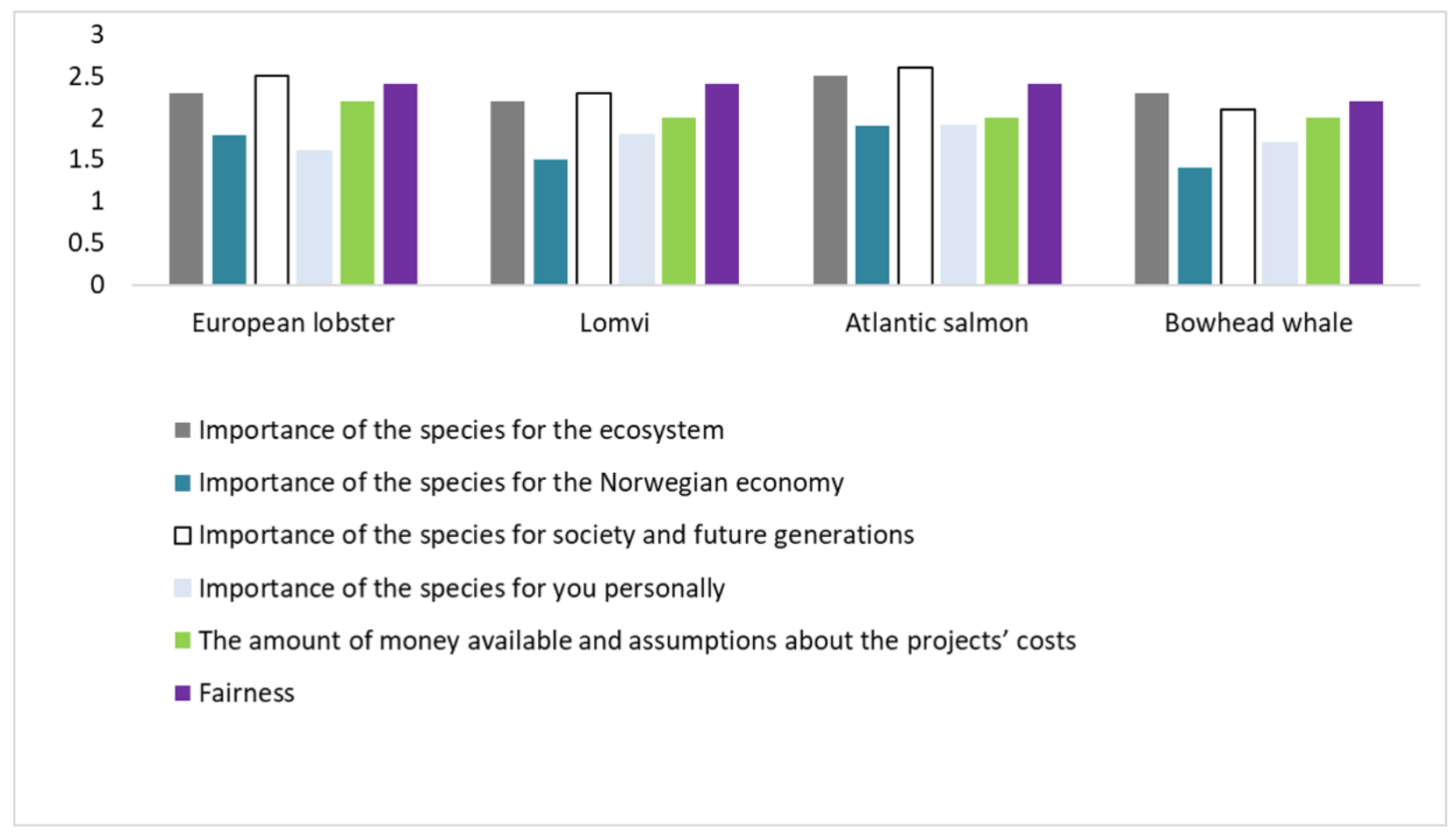

Figure 3b) Average importance of the factors influencing valuation in the focal group 


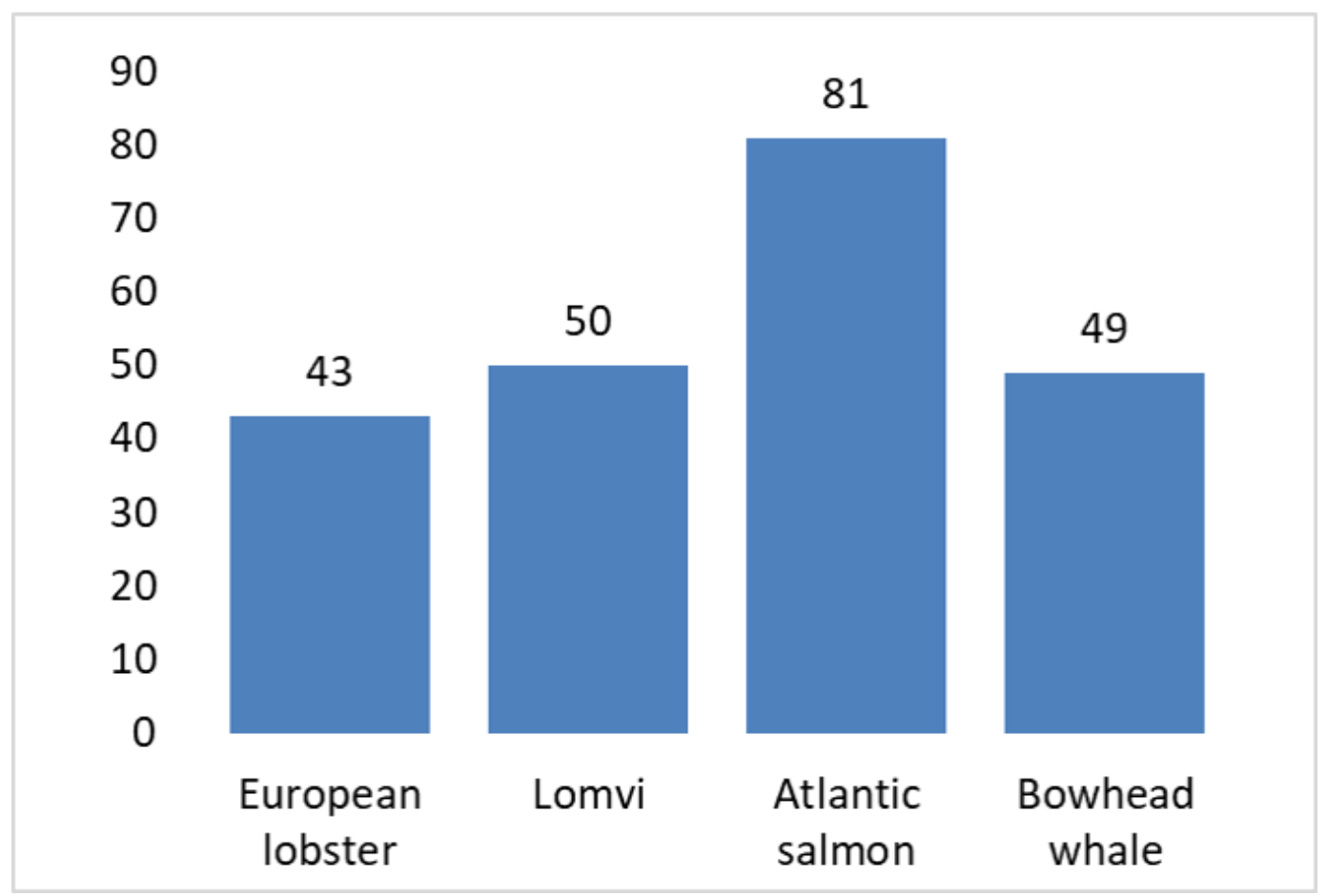

Figure 3c) Total number of respondents (all groups) who have chosen the species in the question 12 